\title{
Fatigue, Fretting Fatigue and Corrosion Characteristics of Biocompatible Beta Type Titanium Alloy Conducted with Various Thermo-Mechanical Treatments
}

\author{
Toshikazu Akahori ${ }^{1}$, Mitsuo Niinomi ${ }^{1}$, Hisao Fukui ${ }^{2}$ and Akihiro Suzuki ${ }^{3}$ \\ ${ }^{1}$ Department of Production Systems Engineering, Toyohashi University of Technology, Toyohashi 441-8580, Japan \\ ${ }^{2}$ Department of Dental Materials Science, School of Dentistry, Aichi-Gakuin University, Nagoya 464-8650, Japan \\ ${ }^{3}$ Titanium Division, Daido Steel Co. Ltd, Tokyo 105-8403, Japan
}

\begin{abstract}
Plain and fretting fatigue properties of $\beta$ type titanium alloy, Ti-29Nb-13Ta-4.6Zr, underwent various thermo-mechanical treatments were investigated in order to judge its potential for biomedical applications. Ti-29Nb-13Ta-4.6Zr aged directly at $723 \mathrm{~K}$ for $259.2 \mathrm{ks}$ after cold rolling shows the greatest fatigue strength in both low cycle fatigue life and high cycle fatigue life regions, and the fatigue limit, which is around $770 \mathrm{MPa}$, is nearly equal to that of hot-rolled Ti-6Al-4V ELI conducted with aging, which is one of representative $\alpha+\beta$ type titanium alloys for biomedical applications. Fretting fatigue strength tends in proportion to Young's modulus. Fretting fatigue limits of the forged bar of Ti-29Nb$13 \mathrm{Ta}-4.6 \mathrm{Zr}$ conducted with solution treatment, and aging at $723 \mathrm{~K}$ after solution treatment are around two thirds and a half of plain fatigue limits, respectively, and those are around $180 \mathrm{MPa}$ and $285 \mathrm{MPa}$, respectively. Passive current densities of the plate of Ti-29Nb-13Ta-4.6Zr conducted with a multi-step-thermo-mechanical treatment, where the cold rolling and solution treatment are repeated 4 times, in $0.5 \% \mathrm{HCl}$ and $\mathrm{Ringer}$ 's solutions are much smaller than that of Ti-29Nb-13Ta-4.6Zr conducted with general thermo-mechanical treatment, and the values are a little smaller than those of forged Ti-15Mo-5Zr-3Al conducted with annealing and hot rolled Ti-6Al-4V ELI conducted with aging.
\end{abstract}

(Received December 3, 2003; Accepted February 23, 2004)

Keywords: titanium-29mass\%niobium-13 mass\%tantalum-4.6mass\%zirconium, tensile properties, plain and fretting fatigue properties, corrosion resistance, biomedical application

\section{Introduction}

Co-Cr alloy and 316L stainless steel have been mainly used for biomedical applications because of their excellent combination of strength and corrosion resistance. ${ }^{1)}$ Toxicity and allergic problems of alloying elements and high Young's modulus of these metallic biomaterials have been, however, pointed out recently. ${ }^{2,3)}$ Titanium and its alloys, in particular, $\alpha+\beta$ type titanium alloys such as Ti-6Al-4V ELI and Ti$6 \mathrm{Al}-7 \mathrm{Nb}$ have been, therefore, used as the most attractive biocompatible metallic materials due to their excellent combination of mechanical properties, corrosion resistance and biocompatibility. Their Young's moduli are, however, still greater comparing with that of the cortical bone. $\beta$ type titanium alloys such as Ti-13Nb-13Zr and Ti-15Mo-5Zr-3Al with low Young's modulus and greater strength have been, therefore, developed for biomedical applications. A new $\beta$ type titanium alloy composed of non-toxic and non-allergic elements like $\mathrm{Nb}$, Ta, and $\mathrm{Zr}$, Ti-29Nb-13Ta-4.6Zr, ${ }^{4-6)}$ has been recently developed in order to achieve lower Young's modulus and excellent mechanical performance.

Implant instrumentations like bone plates, screws and nails, artificial spines, and artificial femoral and hip joints are used under fatigue conditions and sometimes failed due to monotonic load, fatigue and corrosion fatigue. Mechanical performance, in particular, tensile, and plain and fretting fatigue performances are very important factors for titanium alloys for biomedical applications. There are a few papers on fatigue and corrosion resistance of $\beta$ type titanium alloys for biomedical applications although there are many papers on those of $\alpha+\beta$ type titanium alloys such as Ti-6Al-4V ELI and $\mathrm{Ti}-6 \mathrm{Al}-7 \mathrm{Nb}$ for biomedical applications. ${ }^{7-10)}$

Plain and fretting fatigue performances of an alloy are important mechanical properties to confirm the reliability as metallic biomaterials. It is well-known that for titanium alloys these properties are changed according to the microstructures obtained by heat treatments or thermo-mechanical treatments. Therefore, tensile, and plain and fretting fatigue properties of newly developed $\beta$ type titanium alloy, Ti$29 \mathrm{Nb}-13 \mathrm{Ta}-4.6 \mathrm{Zr}$, conducted with various thermo-mechanical treatments were investigated in this study. The basic corrosion characteristics of $\mathrm{Ti}-29 \mathrm{Nb}-13 \mathrm{Ta}-4.6 \mathrm{Zr}$ were also investigated.

\section{Experimental Procedures}

The materials used in this study were forged bars of Ti29Nb-13Ta-4.6Zr (Nb: 29.2, Ta: 12.3, Zr: 4.4, O: 0.10, H: $<0.02$, bal: Ti and $\mathrm{Nb}$ : 31.5, Ta: 11.6, Zr: 4.7, Fe:0.03, O: $0.14, \mathrm{H}:<0.02$, bal: Ti, mass \%) with a diameter of $12 \mathrm{~mm}$ or $20 \mathrm{~mm}$.

The bars of Ti-29Nb-13Ta-4.6Zr (TNTZ) with a diameter of $20 \mathrm{~mm}$ were solutionized at $1063 \mathrm{~K}$ for $3.6 \mathrm{ks}$ in Ar gas atmosphere followed by water quenching (WQ). The solutionized $20 \mathrm{~mm}$ diameter bars are designated as TNTZ $\mathrm{T}_{\mathrm{d} 20}$ here in after. Some of these solutionized bars were cold rolled to the plates with a thickness of $2.5 \mathrm{~mm}$ by a reduction ratio of $87.5 \%$ at ambient temperature. These plates are designated as $\mathrm{TNTZ}_{\mathrm{CR}}$ here in after. The some plates were solutionized at $1063 \mathrm{~K}$ for $3.6 \mathrm{ks}$ in Ar gas atmosphere followed by WQ. These plates will be designated as $\mathrm{TNTZ}_{\mathrm{ST}}$. Both kind of plates were then aged at temperatures between $593 \mathrm{~K}, 673 \mathrm{~K}$ and $723 \mathrm{~K}$ for $259.2 \mathrm{ks}$ in $\mathrm{Ar}$ gas atmosphere followed by WQ. The bars of TNTZ with a diameter of $12 \mathrm{~mm}$ were also solutionized at $1063 \mathrm{~K}$ for $3.6 \mathrm{ks}\left(\mathrm{TNTZ}_{\mathrm{d} 12}\right)$. They were then aged at $723 \mathrm{~K}$ for $172.8 \mathrm{ks}$ after solution treatment at $1063 \mathrm{~K}$ for $3.6 \mathrm{ks}$ in $\mathrm{Ar}$ gas atmosphere followed by WQ. On the other hand, $\mathrm{TNTZ}_{\mathrm{d} 20}$ was conducted with multi-step-thermo- 
mechanical treatment in Ar gas atmosphere followed by WQ, where solution treatment at $1063 \mathrm{~K}$ for $3.6 \mathrm{ks}$ was successively done after each cold rolling up to a reduction ratio of $87.5 \%$, and finally aged at $673 \mathrm{~K}$ for $259.2 \mathrm{ks}$ in $\mathrm{Ar}$ gas atmosphere followed by WQ, in order to improve the corrosion resistance. $\mathrm{TNTZ}_{\mathrm{d} 20}$ was conducted with multistep-thermo-mechanical treatment, and it is designated as $\mathrm{TNTZ}_{\text {multi }}$ here in after.

The constitutional phases of TNTZ conducted with various thermo-mechanical treatments were examined through an Xray diffraction (XRD) analysis and observations using a scanning electron microscopy (SEM) with an energy dispersive X-ray spectroscopy (EDX) and a transmission electron microscopy (TEM). XRD analysis was carried out using a $\mathrm{Cu}$ target with an accelerating voltage of $40 \mathrm{kV}$ and a tube current of $20 \mathrm{~mA}$. SEM and TEM observations were carried out with an acceleration voltage of $20 \mathrm{kV}$ and $200 \mathrm{kV}$, respectively.

Smooth plate specimens with a cross section of $3.0 \times 1.5 \mathrm{~mm}^{2}$ and a gage length of $13 \mathrm{~mm}$ and cylindrical specimens with a diameter of $5.0 \mathrm{~mm}$ and a gage length of $24 \mathrm{~mm}$ for tensile and plain fatigue tests, and smooth plate specimens with a cross section of $3.0 \times 1.5 \mathrm{~mm}^{2}$ and a length of $40 \mathrm{~mm}$ and cylindrical specimens with a diameter of $10 \mathrm{~mm}$ and a thickness of $4 \mathrm{~mm}$ for measuring Young's modulus and corrosion characteristics were machined form the heat-treated plates and bars with their longitudinal directions parallel to the rolling direction. The surface of specimen for measuring corrosion characteristics was fully covered with epoxy resin except for an area of $7.85 \mathrm{~mm}^{2}$ for exposing to each solution, which will be described below. Fretting fatigue specimens have double square bodies with a thickness of $4.0 \mathrm{~mm}$ and a length of $20 \mathrm{~mm}$. Bridge type pads with a span length of $10 \mathrm{~mm}$ for fretting fatigue test made of the same materials as that for the fretting fatigue specimens were used.

Tensile tests were carried out on the tensile specimens finished as stated above using an Instron type machine with an initial cross-head speed of $8.33 \times 10^{-6} \mathrm{~m} / \mathrm{s}$ in air at $295 \mathrm{~K}$. The strain was measured using a clip gage attached to the gage-length area of the specimen and a foil strain gage attached directly to the gage section of the specimen.

Moduli of elasticity on the specimens for measuring modulus of elasticity finished as stated above were measured using a resonance method.

Plain and fretting fatigue tests were carried out on the plain and fretting fatigue specimens using an electro-servohydraulic machine. Each fatigue test was performed at a frequency of $10 \mathrm{~Hz}$ with a stress ratio, $R=0.1$, under the tension-tension mode in air at $295 \mathrm{~K}$ and Ringer's solution at $310 \mathrm{~K}$. The contact pressure was maintained at $153 \mathrm{MPa}$. The maximum cyclic stress, at which the specimen was still unfailed at $10^{7}$ cycles, was defined as the plain or fretting fatigue limit in this study.

Corrosion characteristics was evaluated by anodic polarization test in $5 \% \mathrm{HCl}$ and Ringer's solutions at a temperature of $295 \mathrm{~K}$ which were deaerated by high purity $\mathrm{N}$ gases at a flow rate of $200 \mathrm{~mL} / \mathrm{min}$ for $1.8 \mathrm{ks}$ in order to reduce oxygen content. The specimens were subjected to cathodic treatment at $-0.9 \mathrm{~V}$ with referring to saturated calomel electrode (SCE) for $900 \mathrm{~s}$ to remove oxide film formed on its surface. After the natural electrode potential became stable, anodic polarization tests were conducted at a sweep rate of $20 \mathrm{mV} / \mathrm{min}$ from the natural electrode potential to $2.5 \mathrm{~V}$.

\section{Results and Discussion}

\subsection{Microstructure}

Figure 1 shows XRD profiles of $\mathrm{TNTZ}_{\mathrm{ST}}, \mathrm{TNT}_{\mathrm{CR}}$, and $\mathrm{TNTZ}_{\mathrm{ST}}$ and $\mathrm{TNT}_{\mathrm{CR}}$ conducted with various heat treatments. XRD profiles show no precipitation in $\beta$ phase of TNTZ $_{\mathrm{ST}}$ and TNTZ $\mathrm{CR}$. XRD profiles reveal that $\alpha$ and $\omega$ phases, and $\alpha$ phase are precipitated in $\mathrm{TNTZ}_{\mathrm{ST}}$ aged at $673 \mathrm{~K}$ and $723 \mathrm{~K}$, respectively. While $\mathrm{TNTZ}_{\mathrm{ST}}$ aged at $598 \mathrm{~K}$ has $\omega$ phase. In TNTZ $_{\mathrm{CR}}$ aged at $673 \mathrm{~K}$ and $723 \mathrm{~K}, \alpha$ phase mainly precipitates in $\beta$ phase, and the peak intensity of $\alpha$ phase is much larger than that of $\mathrm{TNTZ}_{\mathrm{ST}}$. The precipitated phase in $\mathrm{TNTZ}_{\mathrm{CR}}$ aged at $598 \mathrm{~K}$ is difficult to confirm because all peaks of $\alpha$ and $\omega$ phases overlap each other with background.

\subsection{Tensile properties}

Tensile properties of $\mathrm{TNTZ}_{\mathrm{ST}}$, $\mathrm{TNTZ}_{\mathrm{CR}}$, and $\mathrm{TNTZ}_{\mathrm{ST}}$ and $\mathrm{TNTZ}_{\mathrm{CR}}$ conducted with various heat treatments are shown in Fig. 2 with those of hot-rolled Ti-6Al-4V ELI conducted with aging ${ }^{11)}$ and forged $\mathrm{Ti}-15 \mathrm{Mo}-5 \mathrm{Zr}-3 \mathrm{Al}$ conducted with annealing $^{12)}$ as comparison. The tensile strength, $0.2 \%$ proof stress and elongation of $\mathrm{TNTZ}_{\mathrm{CR}}$ are $830 \mathrm{MPa}, 755 \mathrm{MPa}$ and $15.2 \%$ on the average, respectively. The tensile strength and $0.2 \%$ proof stress of $\mathrm{TNTZ}_{\mathrm{CR}}$ are around $150 \mathrm{MPa}$ greater than those of $\mathrm{TNTZ}_{\mathrm{ST}}$, which has $650 \mathrm{MPa}$ and $600 \mathrm{MP}$, respectively. On the other hand, the elongation of $\mathrm{TNTZ}_{\mathrm{CR}}$ is a half of $\mathrm{TNTZ}_{\mathrm{ST}}$. The tensile strength and $0.2 \%$ proof stress of all aged $\mathrm{TNTZ}_{\mathrm{ST}}$ and $\mathrm{TNTZ}_{\mathrm{CR}}$ are more than 1.5 times greater than that of $\mathrm{TNTZ}_{\mathrm{ST}}$ and $\mathrm{TNTZ}_{\mathrm{CR}}$. In particular, the elongation of $\mathrm{TNTZ}_{\mathrm{ST}}$ and $\mathrm{TNTZ}_{\mathrm{CR}}$ aged at $598 \mathrm{~K}$, which have super fine $\omega$ phase or $\alpha$ phase, are very poor though the tensile strength and $0.2 \%$ proof stress increase remarkably as compared with those of $\mathrm{TNTZ}_{\mathrm{ST}}$ and $\mathrm{TNTZ}_{\mathrm{CR}}$. On the other hand, the tensile strength and $0.2 \%$ proof stress of $\mathrm{TNTZ}_{\mathrm{ST}}$ and $\mathrm{TNTZ}_{\mathrm{CR}}$ aged at $673 \mathrm{~K}$ and $723 \mathrm{~K}$, which mainly have $\alpha$ phase, tends to be $50 \mathrm{MPa}$ to $200 \mathrm{MPa}$ smaller than those of TNTZ $_{\text {ST }}$ and TNTZ $_{\mathrm{CR}}$ aged at $598 \mathrm{~K}$.

Tensile strength and $0.2 \%$ proof stress of TNTZ $\mathrm{ST}_{\mathrm{ST}}$ aged at $598 \mathrm{~K}$ and $\mathrm{TNTZ}_{\mathrm{CR}}$ aged at $723 \mathrm{~K}$ are nearly equal to those of hot-rolled Ti-6Al-4V ELI conducted with aging after solution treatment, and forged $\mathrm{Ti}-15 \mathrm{Mo}-5 \mathrm{Zr}-3 \mathrm{Al}$ conducted with annealing, and each elongation is over $20 \%$.

\subsection{Young's modulus}

Young's moduli of $\mathrm{TNTZ}_{\mathrm{ST}}, \mathrm{TNTZ}_{\mathrm{CR}}$, and $\mathrm{TNTZ}_{\mathrm{ST}}$ and $\mathrm{TNTZ}_{\mathrm{CR}}$ conducted with various heat treatments are shown in Fig. 3 with those of hot-rolled Ti-6Al-4V ELI conducted with aging ${ }^{13)}$ and forged $\mathrm{Ti}-15 \mathrm{Mo}-5 \mathrm{Zr}-3 \mathrm{Al}$ conducted with annealing. ${ }^{12)}$ The Young's modulus of $\mathrm{TNTZ}_{\mathrm{ST}}$, which is around $63 \mathrm{GPa}$, is pretty similar to that of $\mathrm{TNTZ}_{\mathrm{CR}}$. The Young's modului of forged Ti-15Mo-5Zr-3Al conducted with annealing and hot-rolled Ti-6Al-4V ELI conducted with aging are around $90 \mathrm{GPa}$ and $110 \mathrm{GPa}$, respectively. The Young's moduli of $\mathrm{TNTZ}_{\mathrm{ST}}$ and $\mathrm{TNTZ}_{\mathrm{CR}}$ are a half of that of hot-rolled Ti-6Al-4V ELI conducted with aging, and is twice 
(a)

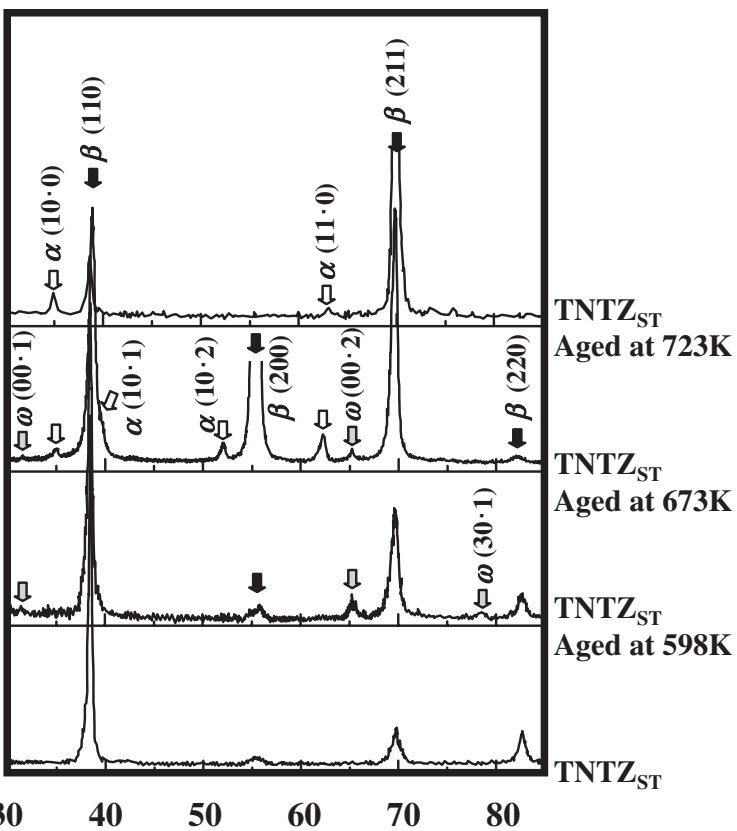

Diffraction angle, $2 \theta /\left(\pi 180^{-1}\right)$ rad

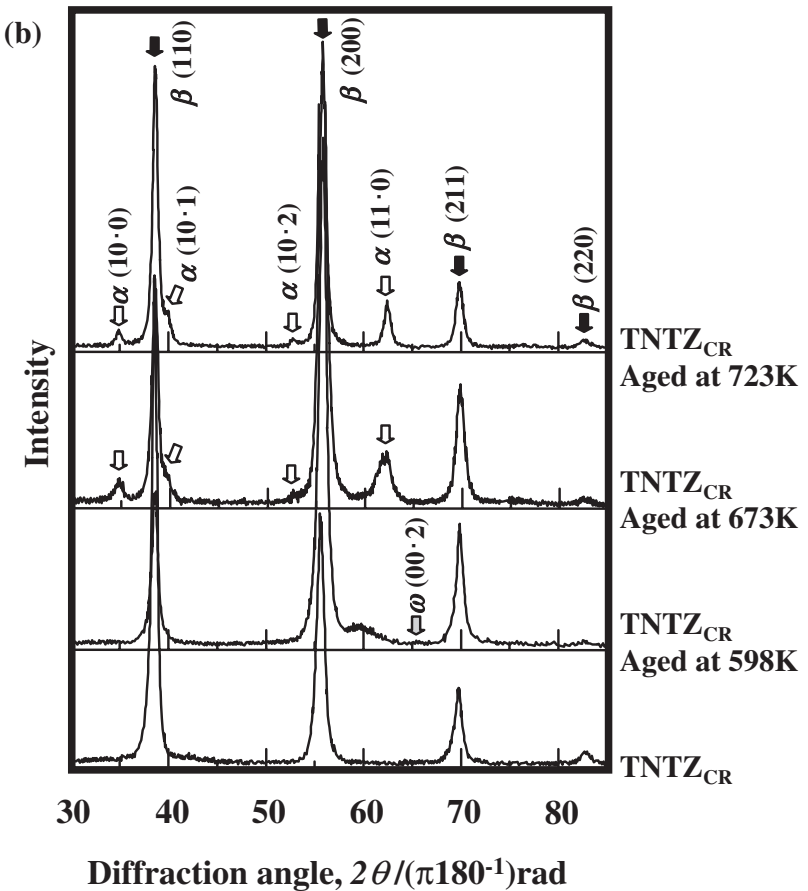

(b)

Diffraction angle, $2 \theta /\left(\pi 180^{-1}\right)$ rad

Fig. 1 X-ray diffraction profiles of $\mathrm{TNTZ}_{\mathrm{ST}}$, $\mathrm{TNTZ}_{\mathrm{CR}}$, and $\mathrm{TNTZ}_{\mathrm{ST}}$ and $\mathrm{TNTZ}_{\mathrm{CR}}$ conducted with aging at $598 \mathrm{~K}$, $673 \mathrm{~K}$ and $723 \mathrm{~K}$ for $259.2 \mathrm{ks}$.

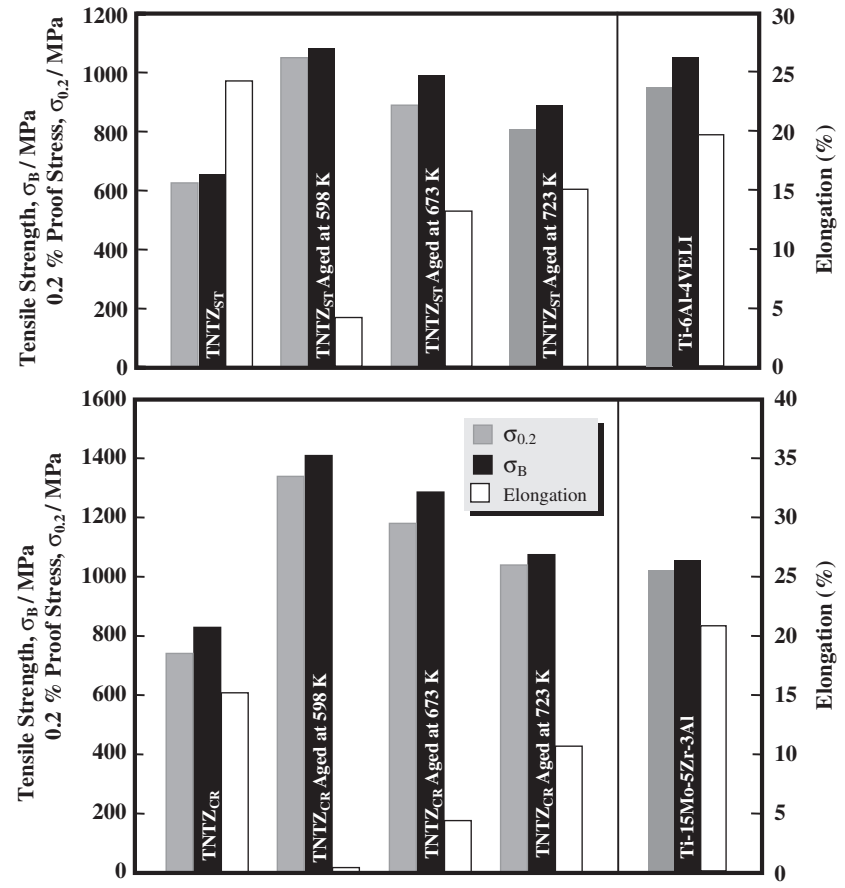

Fig. 2 Tensile properties of $\mathrm{TNTZ}_{\mathrm{ST}}, \mathrm{TNTZ}_{\mathrm{CR}}$, and $\mathrm{TNTZ}_{\mathrm{ST}}$ and $\mathrm{TNTZ}_{\mathrm{CR}}$ conducted with aging at $598 \mathrm{~K}, 673 \mathrm{~K}$ and $723 \mathrm{~K}$ for $259.2 \mathrm{ks}$, hot-rolled Ti-6Al-4V ELI conducted with aging, and forged Ti-15Mo-5Zr-3Al conducted annealing.

as large as that of compact bone. ${ }^{14)}$ The Young's moduli of aged $\mathrm{TNTZ}_{\mathrm{ST}}$ and $\mathrm{TNTZ}_{\mathrm{CR}}$ tend to increase significantly with increasing aging temperature. This trend is almost similar to that of tensile strength and $0.2 \%$ proof stress. The Young's moduli of all aged $\mathrm{TNTZ}_{\mathrm{ST}}$ and $\mathrm{TNTZ}_{\mathrm{CR}}$ are $20 \mathrm{GPa}$
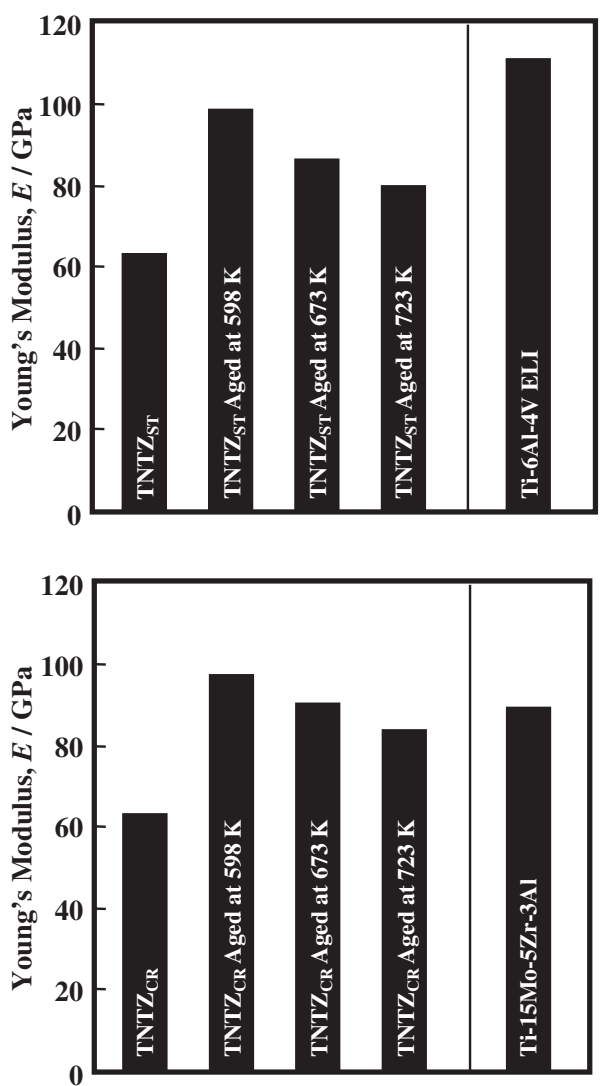

Fig. 3 Young's moduli of $\mathrm{TNTZ}_{\mathrm{ST}}, \mathrm{TNTZ}_{\mathrm{CR}}$, and $\mathrm{TNTZ}_{\mathrm{ST}}$ and $\mathrm{TNTZ}_{\mathrm{CR}}$ conducted with aging at $598 \mathrm{~K}, 673 \mathrm{~K}$ and $723 \mathrm{~K}$ for $259.2 \mathrm{ks}$, hot-rolled Ti-6Al-4V ELI conducted with aging, and forged Ti-15Mo-5Zr-3Al conducted with annealing. 


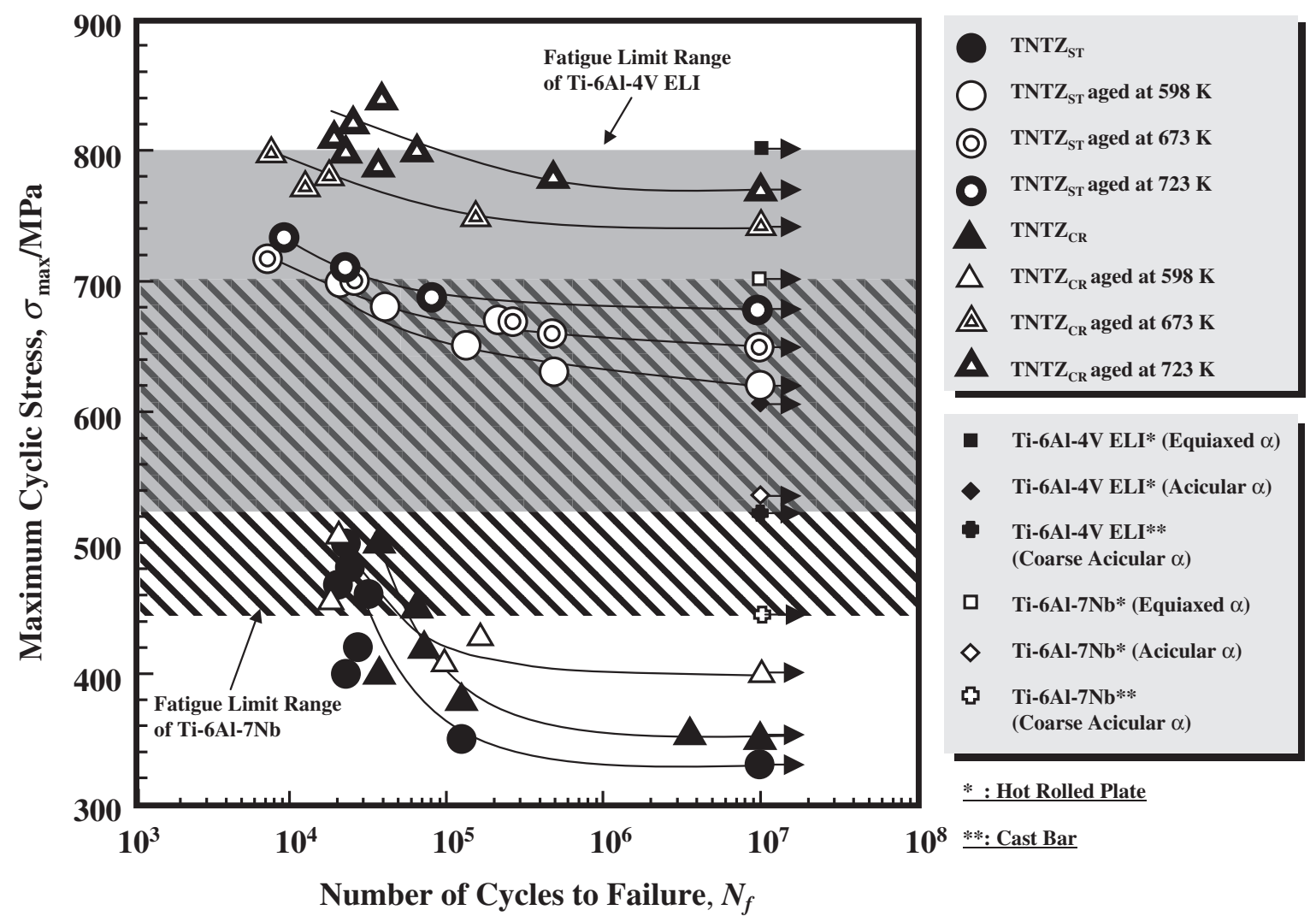

Fig. 4 S-N curves of $\mathrm{TNTZ}_{\mathrm{ST}}$, $\mathrm{TNTZ}_{\mathrm{CR}}$, and $\mathrm{TNTZ}_{\mathrm{ST}}$ and $\mathrm{TNTZ}_{\mathrm{CR}}$ conducted with aging at $598 \mathrm{~K}$, $673 \mathrm{~K}$ and $723 \mathrm{~K}$ for $259.2 \mathrm{ks}$ with those of Ti-6Al-4V ELI and Ti-6Al-7Nb in air.

to $40 \mathrm{GPa}$ greater than those of $\mathrm{TNTZ}_{\mathrm{ST}}$ and $\mathrm{TNTZ}_{\mathrm{CR}}$. The Young's moduli of $\mathrm{TNTZ}_{\mathrm{ST}}$ and $\mathrm{TNTZ}_{\mathrm{CR}}$ aged at $723 \mathrm{~K}$ are relatively smaller than that of hot-rolled Ti-6Al-4V ELI and forged Ti-15Mo-5Zr-3Al. The Young's moduli of TNTZ and $\mathrm{TNTZ}_{\mathrm{CR}}$ aged at $723 \mathrm{~K}$ are smaller than those of TNTZ and $\mathrm{TNTZ}_{\mathrm{CR}}$ aged at $598 \mathrm{~K}$ and $673 \mathrm{~K}$ because $\alpha$ phase is precipitated. Therefore, Young's modulus of TNTZ increases with increasing volume fraction of $\omega$ phase.

\subsection{Fatigue properties}

3.4.1 Plain fatigue strength of $\mathrm{TNTZ}_{\mathrm{ST}}$, $\mathrm{TNTZ}_{\mathrm{CR}}$, and TNTZ $_{\mathrm{ST}}$ and $\mathrm{TNTZ}_{\mathrm{CR}}$ conducted with various aging in air

Maximum cyclic stress-fatigue life (the number of cycles to failure) curves, that is, $\mathrm{S}-\mathrm{N}$ curves, obtained from plain fatigue tests on $\mathrm{TNTZ}_{\mathrm{ST}}$ and $\mathrm{TNTZ}_{\mathrm{CR}}$ conducted with various heat treatments in air are shown in Fig. 4 with ranges of fatigue limits, which are maximum cyclic stresses at which the specimens are not failed at $10^{7}$ cycles, of hotrolled and cast Ti-6Al-4V ELI, ${ }^{11)}$ and Ti-6Al-7Nb. ${ }^{11}$ )

The plain fatigue strength of $\mathrm{TNTZ}_{\mathrm{ST}}$ and $\mathrm{TNTZ}_{\mathrm{CR}}$ aged at temperatures between $593 \mathrm{~K}$ and $723 \mathrm{~K}$ increases remarkably as compared with that of $\mathrm{TNTZ}_{\mathrm{ST}}$ and $\mathrm{TNTZ}_{\mathrm{CR}}$ in both low cycle fatigue life (less than $10^{5}$ cycles) and high cycle fatigue life (more than $10^{5}$ cycles) regions. The plain fatigue strength of aged $\mathrm{TNTZ}_{\mathrm{ST}}$ and $\mathrm{TNTZ}_{\mathrm{CR}}$ rise proportionally with increasing aging temperature. The plain fatigue limit of TNTZ $_{\mathrm{CR}}$ aged at $723 \mathrm{~K}$ is the greatest among the other aged $\mathrm{TNTZ}_{\mathrm{ST}}$ and $\mathrm{TNTZ}_{\mathrm{CR}}$, and it is around $780 \mathrm{MPa}$. The plain fatigue limit of $\mathrm{TNTZ}_{\mathrm{CR}}$ aged at $723 \mathrm{~K}$ is about twice of that of $\mathrm{TNTZ}_{\mathrm{CR}}$. The improvement in plain fatigue strength of TNTZ $_{\mathrm{CR}}$ aged at $723 \mathrm{~K}$ is resulted from increasing tensile strength due to homogenously precipitated fine $\alpha$ phase which leads to increase crack initiation resistance, and relatively greater elongation which improves small fatigue crack propagation resistance. The trend of increment of plain fatigue strength of aged $\mathrm{TNTZ}_{\mathrm{ST}}$ is nearly equal to that of aged $\mathrm{TNTZ}_{\mathrm{CR}}$. The plain fatigue limit of $\mathrm{TNTZ}_{\mathrm{ST}}$ aged at $723 \mathrm{~K}$ is around $680 \mathrm{MPa}$. The plain fatigue limits of TNTZ $_{\mathrm{CR}}$ aged at $673 \mathrm{~K}$ and $723 \mathrm{~K}$ are much greater than those of Ti-6Al-7Nb with equiaxed $\alpha$ and Widmanstätten $\alpha$ structures, and are nearly equal to that of Ti-6Al-4V ELI with equiaxed $\alpha$ structure, which has around $800 \mathrm{MPa}$.

Fatigue fracture surface of $\mathrm{TNTZ}_{\mathrm{CR}}$ aged at $723 \mathrm{~K}$ in high cycle fatigue life region is shown in Fig. 5. The crack initiation site is at the surface of specimen as shown in Fig. 5(a). The main crack propagates vertical to the stress axis, and then propagates parallel to the stress axis with forming a number of striations with a width of around $185 \mathrm{~nm}$ as shown in Figs. 5(b) and (c). This is due to the strong texture with crystals aligned normal to the rolling direction. Then, the crack deflects cyclically in stable fatigue crack propagation area, which results in increasing fatigue crack propagation life. Therefore, it is considered that the stable crack propagation area composed of striations in $\mathrm{TNTZ}_{\mathrm{CR}}$ aged at $673 \mathrm{~K}$ and $723 \mathrm{~K}$ is much greater than that in the other $\mathrm{TNTZ}_{\mathrm{ST}}$ or $\mathrm{TNTZ}_{\mathrm{CR}}$.

Fatigue crack of $\mathrm{TNTZ}_{\mathrm{ST}}$ aged at $598 \mathrm{~K}$ initiated at 

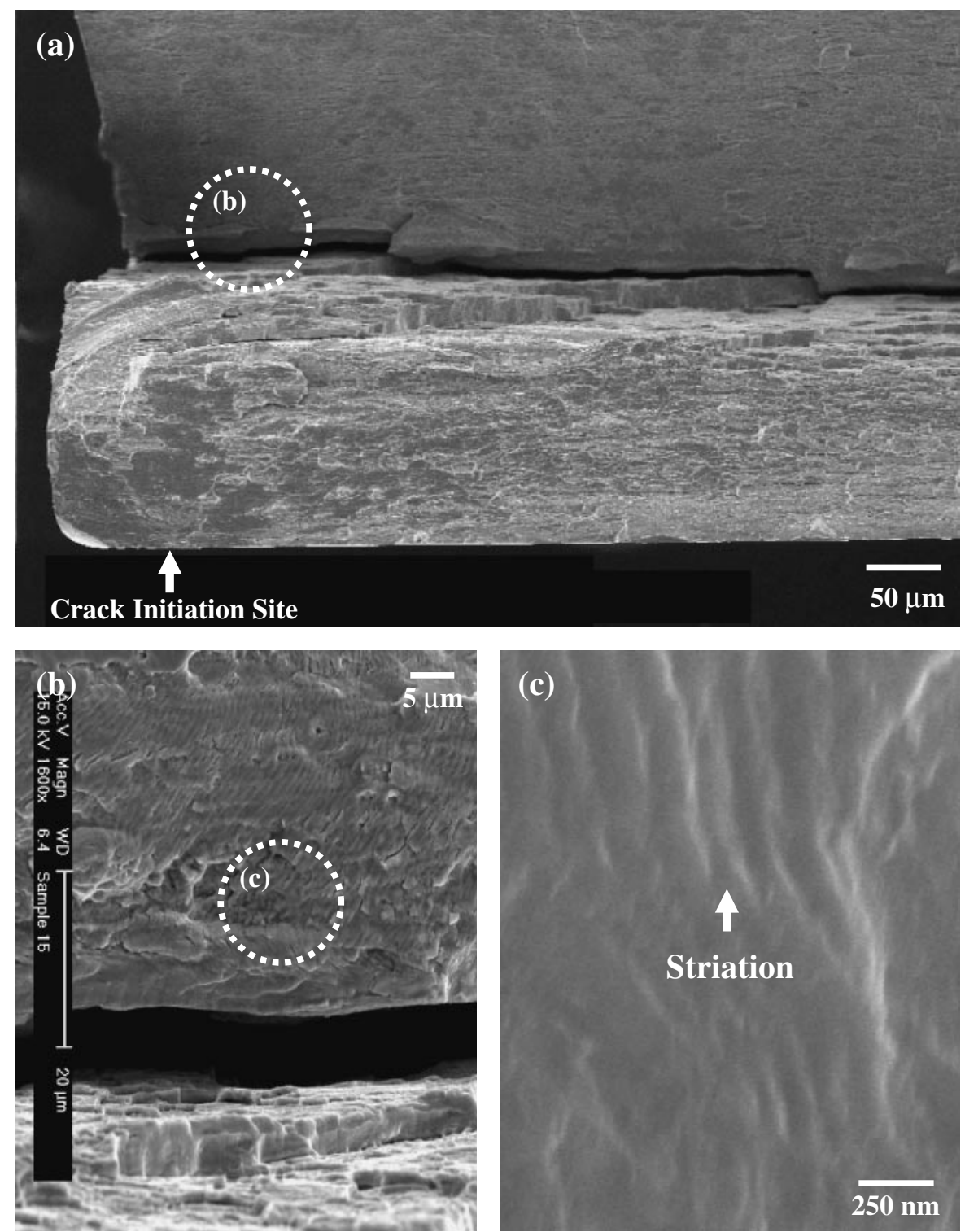

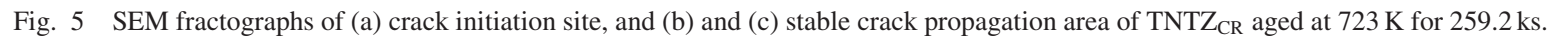

subsurface due to slip plane decohesion, which initiated near $\omega$ phase because $\omega$ phases in $\beta$ phase were super fine and their volume fraction was relatively greater in high cycle fatigue life region. Therefore, slip may not move actively in or near $\omega$ phase, which leads to the dislocation accumulation near the $\omega$ phases. However, further investigation is needed to make sure on this point. In this case, the remarkable change in fatigue life depending on the crack initiation site may not occur.

\subsubsection{Plain fatigue strength of $\mathrm{TNTZ}_{\mathrm{ST}}$ and aged TNTZ $_{\text {ST }}$ in Ringer's solution}

S-N curves obtained from fretting fatigue tests on TNTZ $_{\mathrm{ST}}$ and TNTZ $_{\mathrm{ST}}$ aged at $673 \mathrm{~K}$ in Ringer's are shown in Fig. 6 with those of $\mathrm{TNTZ}_{\mathrm{ST}}$ and $\mathrm{TNTZ}_{\mathrm{ST}}$ aged at $673 \mathrm{~K}$ in air already shown in Fig. 4. The fatigue strength in Ringer's solution is equal to that in air for both as-solutionized and aged conditions. Therefore, the fatigue strength of TNTZ is not degraded in Ringe's solution.

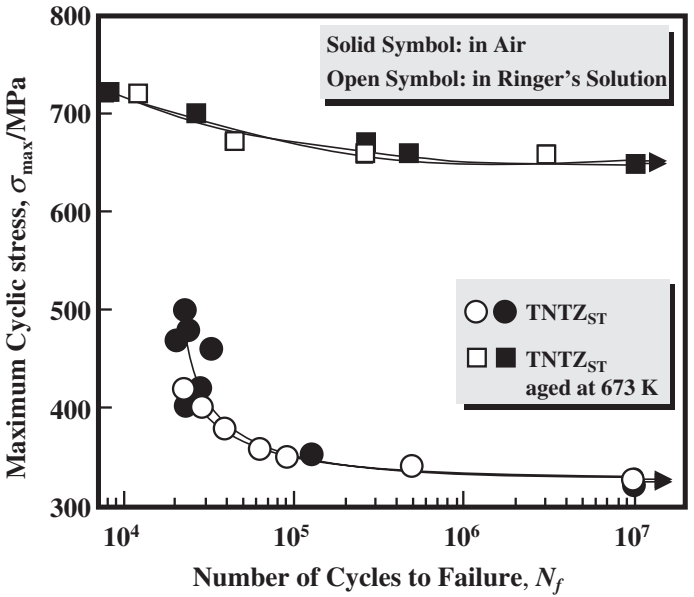

Fig. 6 S-N curves of $\mathrm{TNTZ}_{\mathrm{ST}}$ and $\mathrm{TNTZ}_{\mathrm{ST}}$ aged at $673 \mathrm{~K}$ for $259.2 \mathrm{ks}$ in air and Ringer's solution. 


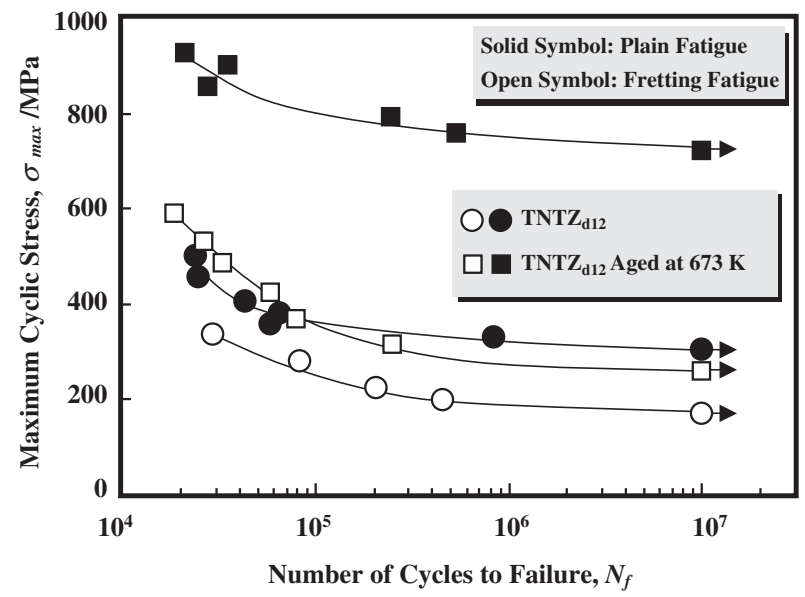

Fig. 7 S-N curves of forged $\mathrm{TNTZ}_{\mathrm{d} 12}$ and $\mathrm{TNTZ}_{\mathrm{d} 12}$ conducted with aging at $673 \mathrm{~K} 259.2 \mathrm{ks}$ obtained from plain fatigue and fretting fatigue tests in air.

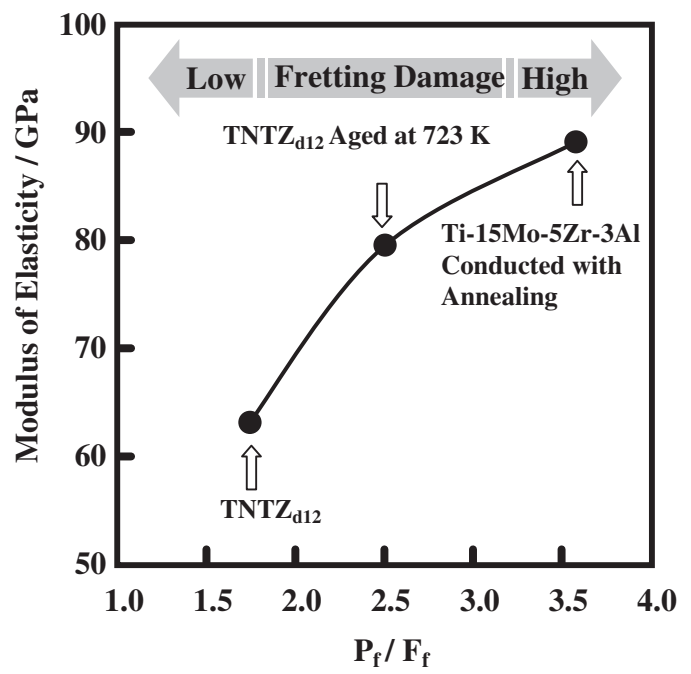

Fig. 8 Relationships between the ratio of fretting damage, $P_{\mathrm{f}} / F_{\mathrm{f}}$, and modulus of elasticity of TNTZ $\mathrm{d}_{12}, \mathrm{TNTZ}_{\mathrm{d} 12}$ conducted with aging at $723 \mathrm{~K}$ $172.8 \mathrm{ks}$ and forged Ti-15Mo-5Zr-3Al conducted with annealing. $P_{\mathrm{f}}$ and $F_{\mathrm{f}}$ indicate plain fatigue limit and fretting fatigue limit, respectively.

\subsubsection{Plain and fretting fatigue strength of $\mathrm{TNTZ}_{\mathrm{d} 12}$ and aged $\mathrm{TNTZ}_{\mathrm{d} 12}$ in air}

S-N curves obtained from plain and fretting fatigue tests on $\mathrm{TNTZ}_{\mathrm{d} 12}$ and aged $\mathrm{TNTZ}_{\mathrm{d} 12}$ in air are shown in Fig. 7. The plain fatigue limits of $\mathrm{TNTZ}_{\mathrm{d} 12}$ and $\mathrm{TNTZ}_{\mathrm{d} 12}$ aged at $723 \mathrm{~K}$ for $172.8 \mathrm{ks}$ after solution treatment were around $330 \mathrm{MPa}$ and $715 \mathrm{MPa}$, respectively. The fretting fatigue strength of $\mathrm{TNTZ}_{\mathrm{d} 12}$ conducted with solution treatment is around two thirds of its plain fatigue strength in both low cycle fatigue life and high cycle fatigue life regions. The fretting fatigue limit of $\mathrm{TNTZ}_{\mathrm{d} 12}$ is around $180 \mathrm{MPa}$. On the other hand, the fatigue limit of $\mathrm{TNTZ}_{\mathrm{d} 12}$ aged at $723 \mathrm{~K}$ for $172.8 \mathrm{ks}$ falls to around $40 \%$ of its plain fatigue limit, that is around $285 \mathrm{MPa}$. The difference in fretting fatigue limits between $\mathrm{TNTZ}_{\mathrm{d} 12}$ and $\mathrm{TNTZ}_{\mathrm{d} 12}$ aged at $723 \mathrm{~K}$ for $172.8 \mathrm{ks}$ are around $120 \mathrm{MPa}$ although that in plain fatigue is around $385 \mathrm{MPa}$.

In fretting fatigue in air, the ratio of fretted damage, $P_{\mathrm{f}} / F_{\mathrm{f}}$, where $P_{\mathrm{f}}$ and $F_{\mathrm{f}}$ are the plain fatigue limit and the fretting

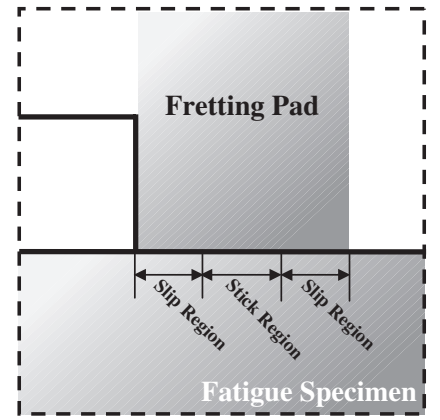

(a) Low Contact Pressure

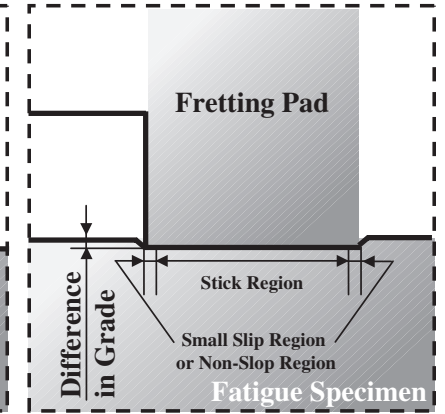

(b) High Contact Pressure
Fig. 9 Schematic drawing of relationship between fretting pad and specimen in material with low Young's modulus during fretting fatigue test at (a) low and (b) high contact pressure.

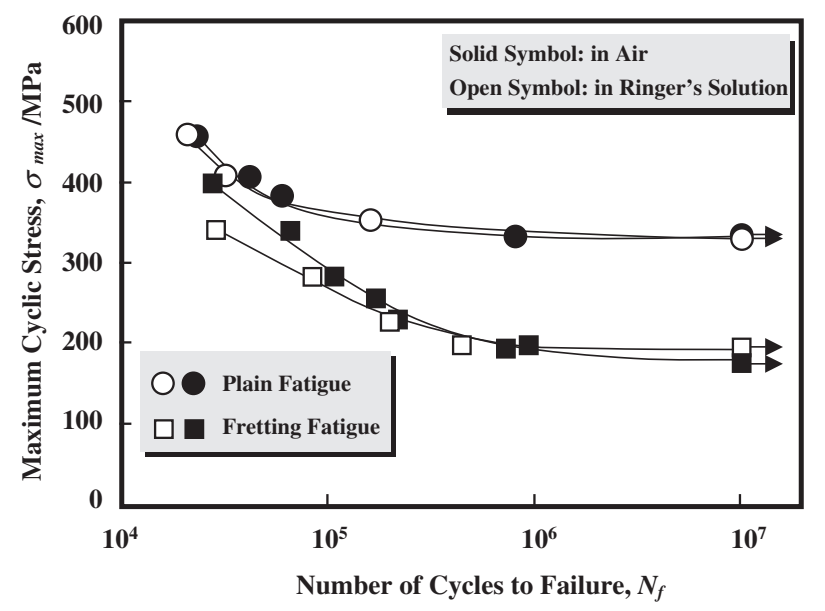

Fig. $10 \mathrm{~S}-\mathrm{N}$ curves of $\mathrm{TNTZ}_{\mathrm{d} 12}$ obtained from plain fatigue and fretting fatigue tests in air and Ringer's solution.

fatigue limit, respectively increases with increasing elastic modulus as shown in Fig. 8, where relationship between $P_{\mathrm{f}} / F_{\mathrm{f}}$ and Young's modulus of forged Ti-15Mo-5Zr-3Al conducted with annealing ${ }^{12)}$ is also shown for comparison. $P_{\mathrm{f}} / F_{\mathrm{f}}$ increases proportionally with increasing Young's modulus. Fretting fatigue crack generally initiates at the boundary between slip and stick region on the specimen surface, where maximum frictional force occurred. ${ }^{15-17)}$ There is a possibility for cyclic action of the pad to be restricted in TNTZ especially in high contact pressure like the case in this study because of lower modulus of elasticity as schematically shown in Fig. 9. The fretting area of TNTZ in high contact pressure is for the most part dominated by stick region. The fretting damage of low rigidity metallic material may decrease with increasing contact pressure.

\subsubsection{Plain and fretting fatigue strength of $\mathrm{TNTZ}_{\mathrm{d} 12}$ in Ringer's solution}

S-N curves obtained from plain and fretting fatigue tests on $\mathrm{TNTZ}_{\mathrm{d} 12}$ in air and Ringer's solution are shown in Fig. 10. The plain fatigue strength of $\mathrm{TNTZ}_{\mathrm{d} 12}$ in Ringer's solution is nearly equal to that in air. The same trends can be seen in $\mathrm{TNTZ}_{\mathrm{ST}}$ and $\mathrm{TNTZ}_{\mathrm{ST}}$ aged at $673 \mathrm{~K}$ as already shown in Fig. 7. However, the fretting fatigue strength of $\mathrm{TNTZ}_{\mathrm{d} 12}$ conducted with ST in Ringer's solution is greater than that in 


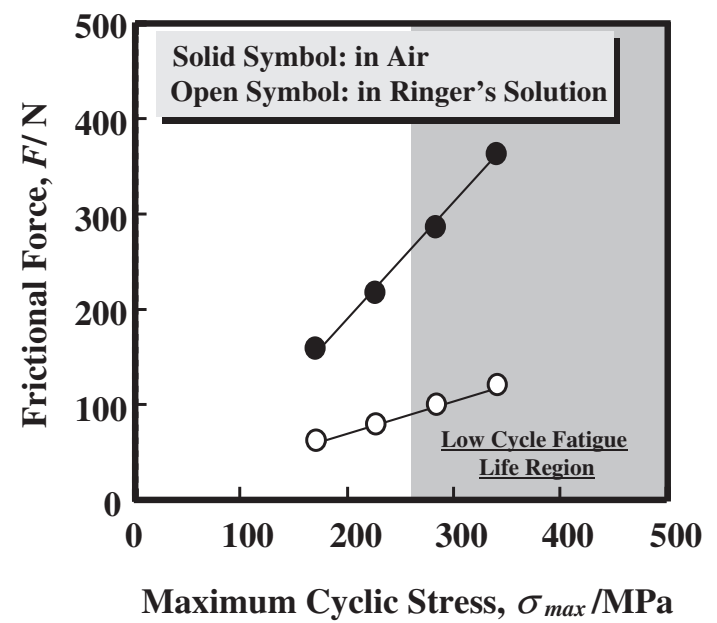

Fig. 11 Relationships between frictional force, $F$, and maximum cyclic stress, $\sigma_{\max }$, of $\mathrm{TNTZ}_{\mathrm{d} 12}$ in air and Ringer's solution.

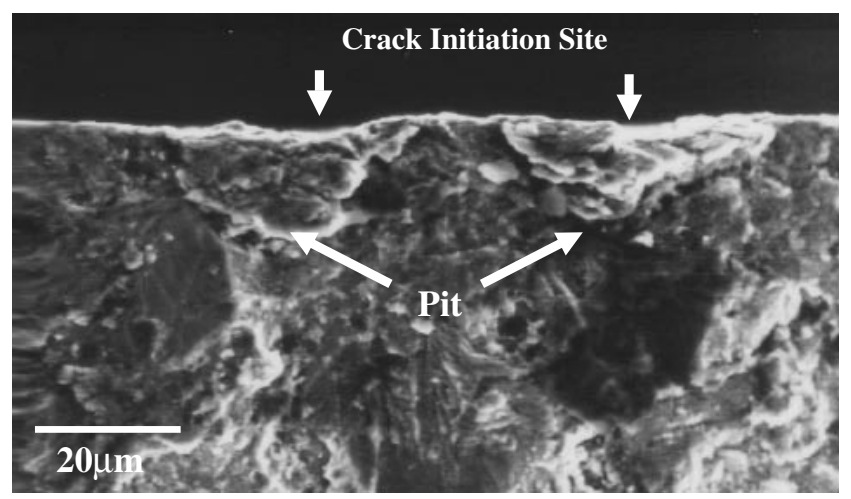

Fig. 12 SEM fractograph of $\mathrm{TNTZ}_{\mathrm{d} 12}$ obtained from fretting fatigue tests in Ringer's solution in high cycle fatigue life region.

air in low cycle fatigue life region, but a little lower than that in air in high cycle fatigue life region. The effect of Ringer's solution as a lubricant is relatively greater in low cycle fatigue region, where the frictional force in Ringer's solution is about one third of that in air (Fig. 11), while effect of Ringer's solution as corrosive agent is relatively greater in high cycle fatigue life region where fretting fatigue crack initiates from pit formed on its surface (Fig. 12). For fretting fatigue of $\mathrm{TNTZ}_{\mathrm{d} 12}$ in Ringer's solution, the passive film on the specimen surface is broken by fretting action, and as a result, corrosion pits that lead to decrease fretting fatigue strength in high cycle fatigue life region, are formed on its surface.

\subsection{Corrosion characteristics in $5 \% \mathrm{HCl}$ and Ringer's solutions}

Figure 13 shows the anodic polarization curves of $\mathrm{TNTZ}_{\mathrm{ST}}, \mathrm{TNTZ}_{\mathrm{ST}}$ aged at $673 \mathrm{~K}$ for $259.2 \mathrm{ks}, \mathrm{TNTZ}_{\text {multi }}$ and $\mathrm{TNTZ}_{\text {multi }}$ aged at $673 \mathrm{~K}$ for $259.2 \mathrm{ks}$ obtained in $5 \% \mathrm{HCl}$ solution with that of hot-swaged Ti-30Nb-10Ta-5Zr, ${ }^{18)}$ which has $0.2 \% \mathrm{O}$ and mirror surface produced by buff polishing, fabricated by powder metallurgy processing (hereafter Ti-3010-5). The current density increases at the low potential

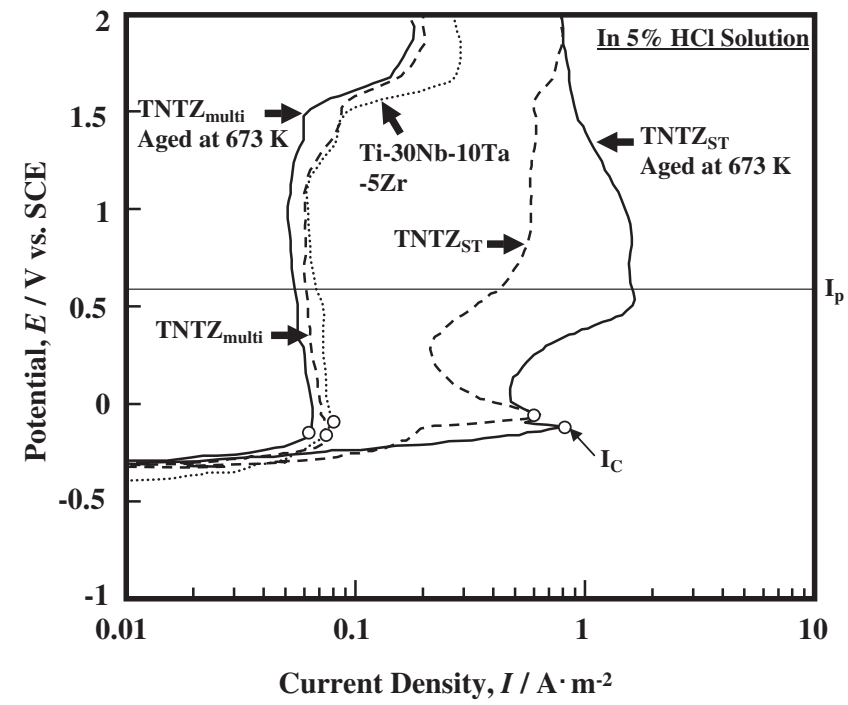

Fig. 13 Anodic polarization curves of $\mathrm{TNTZ}_{\mathrm{ST}}$, $\mathrm{TNTZ}_{\mathrm{ST}}$ aged at $673 \mathrm{~K}$ for $259.2 \mathrm{ks} \mathrm{TNTZ}$ multi, $\mathrm{TNTZ}_{\text {multi }}$ aged at $673 \mathrm{~K}$ for $259.2 \mathrm{ks}$ and hot swaged $\mathrm{Ti}-30 \mathrm{Nb}-10 \mathrm{Ta}-5 \mathrm{Zr}$ in $5 \% \mathrm{HCl}$ solution at $310 \mathrm{~K}$.

region, and the passive current density of $\mathrm{TNTZ}_{\mathrm{ST}}$ is a little higher than that of $\mathrm{TNTZ}_{\mathrm{ST}}$ aged at $673 \mathrm{~K}$ for $259.2 \mathrm{ks}$, although the both critical current densities, $I_{\mathrm{c}}$, are nearly the same, that is around $0.7 \mathrm{~A} \cdot \mathrm{m}^{-2}$. However, the corrosion resistance of $\mathrm{TNTZ}_{\mathrm{ST}}$ and $\mathrm{TNTZ}_{\mathrm{ST}}$ aged at $673 \mathrm{~K}$ for $259.2 \mathrm{ks}$ is lower than that of Ti-30-10-5. In general, the corrosion resistance of $\mathrm{Ti}$ is expected to be improved by alloying $\mathrm{Nb}, \mathrm{Zr}$ and $\mathrm{Ta}^{19)}$ However, the behaviors of anodic polarization curves of $\mathrm{TNTZ}_{\mathrm{ST}}$ and $\mathrm{TNTZ}_{\mathrm{ST}}$ aged at $673 \mathrm{~K}$ for $259.2 \mathrm{ks}$ are pretty different from that of Ti-30-10-5. The critical current densities of $\mathrm{TNTZ}_{\mathrm{ST}}$ and $\mathrm{TNTZ}_{\mathrm{ST}}$ aged at $673 \mathrm{~K}$ for $259.2 \mathrm{ks}$ are ten times greater than that of Ti-30-10-5. On the other hand, $I_{\mathrm{c}}$ and passive current densities at $0.6 \mathrm{~V}, I_{\mathrm{p}}$, of $\mathrm{TNTZ}_{\text {multi }}$ and $\mathrm{TNTZ}_{\text {multi }}$ aged at $673 \mathrm{~K}$ for $259.2 \mathrm{ks}$ are very similar to that of $\mathrm{Ti}-30-10-5$. This trend was the same in Ringer's solution.

Figure 14 shows SEM micrographs and elemental mapping images of $\mathrm{TNTZ}_{\mathrm{ST}}$ and $\mathrm{TNTZ}_{\text {multi. The elemental }}$ mapping images using black and write colors shown in Figs. 14(b) and (f) show the change in concentration of alloying element where the concentration of each element increases with increasing the dark image.

The stripe lines on surface of $\mathrm{TNTZ}_{\mathrm{ST}}$ parallel to the rolling direction shown in Fig. 14(b) correspond to the change in Ta content ratio (Fig. 14(c)). It is considered that the fluctuation of Ta concentration, which may be appeared during the processing composed of melting and hot forging, is aligned with rolling direction. The difference between the maximum level and the minimum level of Ta concentration was found to be around 3 mass\% by EDX. The fluctuation of $\mathrm{Nb}$ or $\mathrm{Zr}$ concentration was not observed in this study. It was difficult to eliminate the stripe lines parallel to rolling direction by solution treatment or aging conducted in this study. The stripe lines on the surface of $\mathrm{TNTZ}_{\text {multi }}$ parallel to rolling direction related with the fluctuation of Ta concentration is eliminated completely (Figs. 14(f) and (g)). Therefore, each alloying element, in particular, Ta is dis- 
TNTZ $_{\text {ST }}$

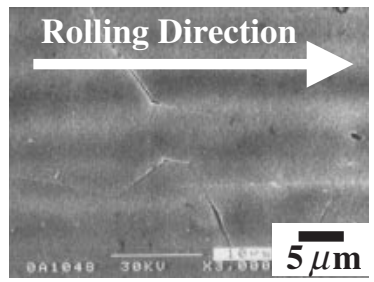

(a) SEM Micrograph

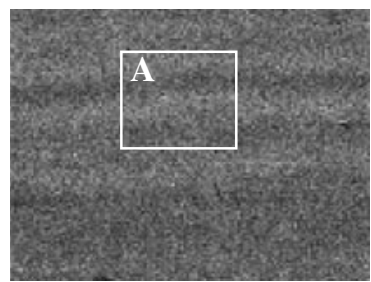

(b) EMI

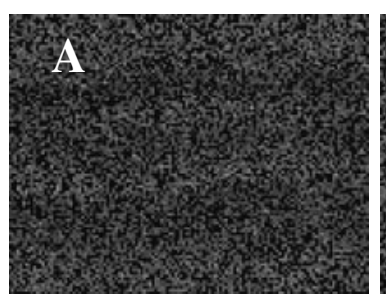

(c) EMI of Ta
TNTZ $_{\text {multi }}$

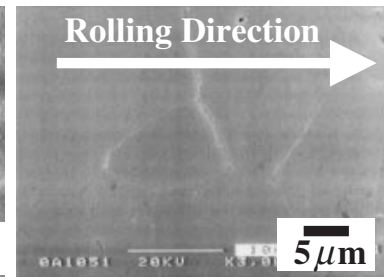

(d) SEM Micrograph

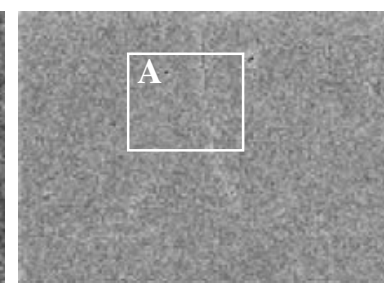

(f) EMI

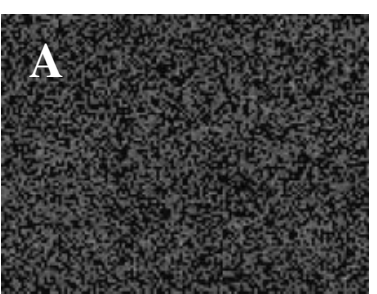

(g) EMI of Ta
Fig. 14 SEM micrographs and elemential mapping images (EMI) of TNTZ $_{\mathrm{ST}}$ and $\mathrm{TNTZ}_{\text {multi }}$.

tributed homogeneously. As a result, it is considered that the corrosion resistance of $\mathrm{TNTZ}_{\text {multi }}$ is improved remarkably.

Figure 15 shows relationship between passive current densities, $I_{\mathrm{p}}$, in $5 \% \mathrm{HCl}$ and Ringer's solutions of $\mathrm{TNTZ}_{\mathrm{ST}}$, $\mathrm{TNTZ}_{\mathrm{ST}}$ aged at $673 \mathrm{~K}$ for $259.2 \mathrm{ks}, \mathrm{TNTZ}_{\text {multi }}$ and aged $\mathrm{TNTZ}_{\text {multi }}$ at $673 \mathrm{~K}$ for $259.2 \mathrm{ks}$ with those of hot-rolled Ti$6 \mathrm{Al}-4 \mathrm{~V}$ ELI conducted with aging, ${ }^{18)}$ hot-rolled Ti-5Al-2.5Fe conducted with aging ${ }^{18)}$ and forged $\mathrm{Ti}-13 \mathrm{Mo}-5 \mathrm{Zr}-3 \mathrm{Al}$ conducted with annealing. ${ }^{18)} I_{\mathrm{p}}$ of TNTZ $\mathrm{THulti}_{\text {and }} \mathrm{TNTZ}_{\text {multi }}$ aged at $673 \mathrm{~K}$ in $0.5 \% \mathrm{HCl}$ and Ringer's solutions are very low values less than $0.1 \mathrm{~A} \cdot \mathrm{m}^{-2}$ and have a correlation each other. While those of $\mathrm{TNTZ}_{\mathrm{ST}}$ and $\mathrm{TNTZ}_{\mathrm{ST}}$ aged at $673 \mathrm{~K}$ are significantly scattered. They are much greater than that of Ti$5 \mathrm{Al}-2.5 \mathrm{Fe}$, and are a little smaller than that of Ti-15Mo-5Zr$3 \mathrm{Al}$ or Ti-6Al-4V ELI.

\section{Conclusions}

Plain and fretting fatigue properties of newly developed $\beta$ type titanium alloy, Ti-29Nb-13Ta-4.6Zr, conducted with various heat treatments were investigated in this study. The basic corrosion characteristics of Ti-29Nb-13Ta-4.6Zr were also investigated. The following results were obtained.

(1) $\mathrm{TNTZ}_{\mathrm{CR}}$ aged at $723 \mathrm{~K}$ for $259.2 \mathrm{ks}$ shows the greatest fatigue strength in both low cycle fatigue and high cycle fatigue life regions, and the fatigue limit, which is around $770 \mathrm{MPa}$, is nearly equal to that of hot-rolled Ti$6 \mathrm{Al}-4 \mathrm{~V}$ ELI conducted with aging.

(2) Fretting fatigue limits of the forged bar of Ti-29Nb-

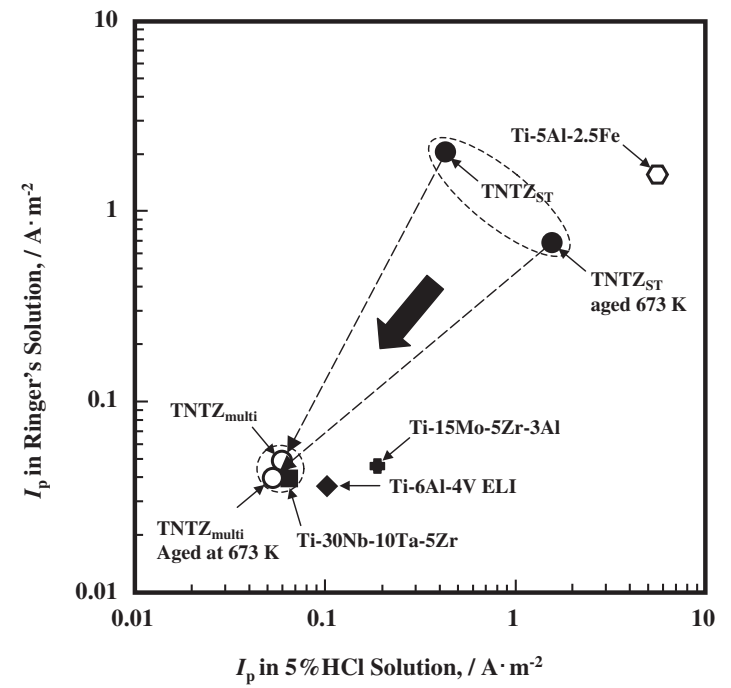

Fig. 15 Comparison of passive current density, $I_{\mathrm{p}}$, of each titanium alloy in $5 \% \mathrm{HCl}$ and Ringer's solution.

$13 \mathrm{Ta}-4.6 \mathrm{Zr}$ conducted with solution treatment $\left(\mathrm{TNTZ}_{\mathrm{d} 12}\right)$, and aging at $723 \mathrm{~K} 172.8 \mathrm{ks}$ after solution treatment are around $180 \mathrm{MPa}$ and $300 \mathrm{MPa}$, respectively, which are much lower than those of plain fatigue limits.

(3) For fretting fatigue of $\mathrm{TNTZ}_{\mathrm{d} 12}$ in Ringer's solution, the passive film on the specimen surface is broken by fretting action, and as a result, corrosion pits that lead to decrease fretting fatigue strength in high cycle fatigue life region, are formed on its surface.

(4) Passive current densities of the forged bars of Ti-29Nb13Ta-4.6Zr conducted with multi-step-thermo-mechanical treatment $\left(\mathrm{TNTZ}_{\text {mult }}\right)$, where the cold rolling and solution treatment are repeated 4 times, in $0.5 \% \mathrm{HCl}$ and Ringer's solutions are much smaller than those of Ti$29 \mathrm{Nb}-13 \mathrm{Ta}-4.6 \mathrm{Zr}$ conducted with general heat treatments, and the values are a little smaller than those of forged $\mathrm{Ti}-15 \mathrm{Mo}-5 \mathrm{Zr}-3 \mathrm{Al}$ conducted with annealing and hot rolled Ti-6Al-4V ELI conducted with aging.

\section{Acknowledgments}

Some parts of this study are supported by NED (New Energy and Industrial Technology Development Organization, Tokyo, Japan), Grant-in-Aid for Promoting Scientific Frontier Research from Ministry Education, Science and Culture (Tokyo, Japan), Grant-in-Aid for Scientific Research from Japan Society for Promotion of Science (Tokyo, Japan), Mitsubishi Foundation (Tokyo, Japan), Kotai Fundation (Tokyo, Japan), The Iron and Steel Institute of Japan (Tokyo, Japan), The Light Metal Education Foundation (Osaka, Japan), Suzuki Foundation (Hamamatsu, Japan) and the Grant for the Excellent Research Project of Research Center for Future Technology, Toyohashi University of Technology. T A would like to express great thanks to Professor Daniel Eylon, The University of Dayton (Ohio, USA) for his assistance to complete this paper. 


\section{REFERENCES}

1) M. Niinomi: Mat. Mater. Trans. A 33A (2002) 477-486.

2) Y. Okazaki, K. Kyo, Y. Ito, E. Nishimura and T. Tateishi: Materia Japan 36 (1997) 1092-1099.

3) H. Hamanaka and T. Tsuchiya: Feramu Japan 2 (1997) 30-35.

4) M. Niinomi, T. Hattori, K. Morikawa, T. Kasuga, A. Suzuki, H. Fukui and S. Niwa, Mater. Trans. 43 (2002) 2970-2977.

5) D. Kuroda, M. Niinomi, H. Fukui, M. Morinaga, H. Suzuki and J. Hasegawa: Tetsu-to-Hagane 86 (2000) 32-39.

6) D. Kuroda, M. Niinomi, H. Fukui, H. Suzuki and J. Hasegawa: Tetsuto-Hagane 86 (2000) 40-46.

7) R. Schenk: Titanium in Medicine, Springer, ed. by D. M. Brunette, P. Tengvall, M. Textor and P. Thomesen, (2001) 144-170.

8) B. Gasser: Titanium in Medicine, Springer, ed. by D. M. Brunette, P. Tengvall, M. Textor and P. Thomesen, (2001) 673-701.

9) Y. Okazaki: Materia Japan 37 (1998) 838-842.

10) Y. Okazalo, K. Kyo, Y. Ito and T. Tateishi: Mater. Trans. 38 (1997) 163-170.
11) T. Akahori, M. Niinomi K. Fukunaga and I. Inagaki: Metall. Mater. Trans. A 31A (2000) 1937-1948.

12) M. Niinomi, T. Akahori, S. Nakamura, H. Fukui and H. Suzuki: Tetsuto-Hagane 88 (2002) 567-574.

13) M. Niinomi: Materia Japan 37 (1998) 843-846.

14) J. A. Davidson, F. S. Gergette: State of the Art Materials for Orthopedic Devices, Soc. Manufacturing Engineers EM87-122 (1987) 1.

15) S. K. Lee, K. Nakazawa, M. Sumita and N. Maruyama: Fretting Fatigue Current Technology and Practices, ASTM ed. by D. W. Hoeppner, V. Chandrasekaran and C. B. Elliott III, (2001) pp. 199-212.

16) M. Sumita, N. Maruyama and K. Nakazawa: Fretting Fatigue, ESIS ed. by R. B. Waterhouse and T. C. Lindley, (2001) pp. 351-361.

17) N. Maruyama, M. Sumita and K. Nakazawa: Tetsu-to-Hagane 76 (1990) 262-269.

18) K. Ishimizu, M. Niinomi, T. Akahori, H. Fukui and H. Suzuki: Collected Abstracts of the 2002 Fall Meeting of the Japan Inst. of Light Metals (2002) p. 365.

19) Y. Okazaki, A. Ito, T. Tateishi and Y. Ito: J. Japan Inst. Metals 57 (1993) 338-346. 